\title{
LongForm or Microcontent? An analysis of supports for digital content courseware
}

\author{
¿LongForm o Microcontenido? análisis de soportes para \\ materiales didácticos digitales
}

\author{
Nicole Santana Gomes \\ Universidade Federal de Itajubá. Itajubá Minas Gerais, Brasil. \\ nicole_sgomes@unifei.edu.br \\ Ronei Ximenes Martins \\ Universidade Federal de Lavras. Lavras, Minas Gerais, Brasil. \\ rxmartins@ufla.br \\ Daniela Simone Azevedo \\ Secretaria Municipal de Educação. Betim Minas Gerais, Brasil. \\ danielaazevedo@semed.betim.mg.gov.br
}

\begin{abstract}
The use of digital educational resources has expanded considerably, including in the context of the COVID-19 pandemic. In the educational materials used in these resources, the Microcontent (MC) format predominates, with its fragmented and small information units. So, we ask: can the LongForm (LF) format, which allows the presentation of dense and extensive content, be a viable alternative to $\mathrm{MC}$, when applied to complex educational content, specific to undergraduate courses? The LF, hypothetically, can offer better support for higher distance education courses. To answer the question, an educational activity, elaborated in both formats, was applied to 67 students from a university of Minas Gerais state, in Brazil. The observation of student activity revealed their preferences: MC has shown to be good for building learning with smaller materials in both size and content complexity, but LF was more appropriated when dealing with complex, dense, multimedia-requiring contents to facilitate understanding. It was confirmed that the LF presents itself as a viable alternative for online studying because it is constituted by a single virtual space where larger texts and varied multimedia resources can be inserted to enrich the educational material and to offer the full content for students.
\end{abstract}

Keywords: Mobile Learning; Instructional materials; Distance Education.

\section{Resumen}

El uso de recursos educativos digitales se ha expandido considerablemente, incluso en el contexto de la pandemia COVID-19. En los materiales didácticos utilizados en estos recursos predomina el formato de Microcontenido (MC), con sus unidades de información fragmentadas y pequeñas. Entonces, nos preguntamos: ¿puede el formato LongForm (LF), que permite la presentación de contenido denso y extenso, ser una alternativa viable al MC, cuando se aplica a contenidos educativos complejos, específicos de la educación superior? El LF, hipotéticamente, puede ofrecer un mejor apoyo para los cursos de educación superior a distancia. Para responder a la pregunta, se aplicó una actividad en ambos formatos a 67 estudiantes de una Universidad de Minas Gerais, que reveló las preferencias de los participantes: el MC demostró ser bueno para la construcción de materiales didácticos de menor tamaño y baja densidad de contenido. El formato LF es apropiado para contenido complejo y se presenta como una alternativa viable para cursos en línea ya que está constituido por un único espacio virtual donde se pueden introducir textos más grandes y diversos recursos multimedia para facilitar la comprensión, enriquecer los materiales didácticos y ofrecer el contenido completo para los estudiantes.

Palabras clave: Tecnología educativa. Material didáctico. Educación a distancia. 


\section{Introduction}

The evolution of educational materials that are utilized in distance education courses is categorized in different generations and is closely related to technological resources available throughout each historical moment. Such evolution happens as a consequence of technological developments, but mainly because of the acceptance of methodologies that innovate the pedagogical mediation. Knowing how to conciliate technological resources and the methodological innovation in the process of teaching can bring forth new strategies to organize the formal education curriculum also may be used as a source of data to guide educational actions in the international context of Coronavirus.

The organization of courses whose desired learning can take place in different places from where the teaching structure is located requires pedagogical mediation provided by digital information and communication technologies (DICT), as well as competent actions by teachers, students and support professionals (Moore, \& Kearsley, 2011). With the technological improvement of digital artifacts and the increase of communication velocity that occurred the last decade on the web, the pedagogical mediation started to be grounded predominantly on devices that are connected to the Internet.

Laptop or desktop computers, cellphones or tablets are examples of technologies that increasingly become more accessible and, since they present constant innovations in their functions, they constitute themselves as a fertile field for the pedagogical mediation that currently happens with integral support of digital technologies. Facing innovation and the many possibilities the Internet and its means provide, the challenge of exploring the DICT for advantage of educational processes is recognized. In this sense, it is assumed that not only the instructional design of the courses mediated by technologies must align itself to the offer platforms, but beside that, the didactic materials must be thought according to the following concepts: usability, adaptability, connection, quickness, readability, loading time, lightness, plainness and others. How like is being observed in current times, the offer of educational contents about these new devices is predominantly formed by learning objects, which conceptual base and creation methodology (Willey, 2002; Amante \& Morgado, 2001) determine that the information should be divided in small units of texts, videos, images and other audiovisual resources that will be identified as Microcontent in this work.

Learning can be the result of the fractioned content offer, according to Gabrielli, Kimani and Cartaci (2006), as long as they allow the contact with the information and also the experimentation and the access rhythm control for the students. However, the Microcontent predominance can, hypothetically, bring forth the mitigation of the study deepening and, consequently, of the content comprehension, if the students do not seek to deep to studying by other sources. Added to this, much has been discussed about the ideal quality and quantity of online information, mainly for communication companies and producers of journalistic content. In the scope of these discussions, digital journalism has inaugurated an alternative to Microcontent, denominated LongForm. This format is characterized by offering deepened information, composed by images, videos, links and infographics, beside texts, which provide, according to Longhi and Winques (2015), a more immersive and deeper experience of the covered content.

According to the education evolution mediated by digital technologies of information and communication, of various user profiles, of new available devices for the mediation

LongForm or Microcontent? An analysis of supports for digital content courseware.

Gomes, N. S.; Martins, R. X. and Azevedo. D. S. Page 2 of 17 
between learner, content and teachers, presentation characteristics, potentialities and limitations of each format, it is considered that, in hypothesis, LongForm can be a viable alternative to Microcontent for educational materials production for online courses.

Based on above, a question arises about what possible contributions the LongForm application, today directed to the journalistic content production, can bring to the production of educational content if compared to the Microcontent format, which is a base for online courses content. The LongForm is considered to be better adjusted to the necessities of working with more complex educational themes, owing to its architecture and composition, that is concerned with density without losing sight of the usability and to the lightness adapted to more recent information and communication technologies, especially that of mobile devices.

In this paper, part of extensive research, there is the presentation of a comparative analysis of Microcontent and LongForm formats applied to the production of materials that are utilized for pedagogical purposes both in Distance Education and in support to the faceto-face courses.

\section{Background Literature}

\subsection{Digital Content Readings}

The onset of new media and digital resources has been altering the relationships built between human being with writing and reading. Currently, the reader is presented a sequential flow of screen texts, in which their boundaries are no longer so visible, allowing the reader to scramble and intersect information. This reading revolution is the result of how people relate themselves to information in use situations with new media and technologies because "[...] each reader, for each one of their readings, in each circumstance, is singular (Chartier, 1999, p. 91)".

With the insertion of DICT in school education, people have begun to learn and develop new ways of relating to information by new platforms and languages. To readers of the digital environment, natives or not, the challenge has arisen to master digital technologies to the point of using them as a facilitating instrument to build knowledge. Digital readers need to know, identify, and make proper use of equipment and controls, ultimately achieving the skills to use technologies in their social practices. Likewise, producing digital content to meet the needs and characteristics of the most diverse audiences is also a challenge.

This research follows the definition of Santaella (2007) when she defines text as a long or short chain of linguistic signs combined together. It is through these arrangements that a book can, at one time, be composed by words, images, graphs, printed illustrations; and it can also be produced in the digital media including other items, such as animations and videos, utilizing the digital language.

Digital language, therefore, allows that all the other languages to blend together, "[...] sounds, words and images that once could only coexist become coordinated in a fluid structures with which the users learn to interact, through participatory actions, as if in a

LongForm or Microcontent? An analysis of supports for digital content courseware.

Gomes, N. S.; Martins, R. X. and Azevedo. D. S. $\quad$ Page 3 of 17 
game" (Santaella, 2007, p. 294). Since digital media is essentially interactive, it demands interaction with the reader, either by clicking or by choosing from navigation options.

The composition of a digital contends for teaching includes items that enrich, illustrate or provoke the reader. One of the items that compose digital information is the hypertext, as a digital document formed by different information blocks interconnected by associative links. Leão (2005) defines these blocks as basic units formed "[...] by different elements, such as texts, images, videos, icons, buttons, sounds, narrations, etc." (Leão, 2005, p. 27).

The hypertext can still be characterized as a self-service text, "partially created by the author, who organizes it; and partially by the readers, who choose the links of their choices, connecting the informational data that interest them the most" (Eisenkraemer, 2006 , p. 05). Due to the many possibilities of navigation and textual reorganization that the use of links allows, it is important that digital content creators worry about the text organization to avoid the clutter of ideas. After all, the "[...] simple attitude of following a series of links is not enough to create a coherent whole in the reader's mind" (Leão, 2005, p. 129).

Each digital educational material can, along with its organizational structure, propose a sequence of paths for student navigation, starting from early stages to more complex ones. Depending on the proposed navigation path and the resources utilized in the production of the didactic materials, students may have more or less complex distance learning experiences, whether they are mobile mediated or not.

Studying through hyperlinks, distributed throughout the educational material, allows and also requires that readers choose the information they want to interact with. Still, within the analogy of self-service, readers will choose at least one among many proposed informative contents, even if at the end of the studies they are not very satisfied with their choices and realize that more choices have made than they could assimilate. Interacting with a computer system involves understanding it, making decisions, solving problems, storing concepts and processing them in order to achieve knowledge.

Teachers, designers and other professionals that work in designing courses and developing digital educational material should, therefore, make sure that hyperlinks have a thematic link with the original content; that they are distributed according to their categories and functions, that range from the presentation of the information about the subject to the deepening and exploration of the offered content; that they appear embedded in the text, highlighting its most important data through colors, keywords or media; and that they are clearly highlighted at the end of sentences or texts, avoiding noises in the process of reading.

The navigation paths, that have inserted as proposals in the digital content, are the result of the author's action, but the decision of which paths to take is in the hands of the readerbrowsers, "[...] because the mouse is with them ultimately (Marchuschi, 2007, p. 185). Marchuschi (2007) states that it does not mean that the predominance of the reading coherence is under the responsibility of the reader, but rather that it directs the movements that lead to the meaning construction. These navigational paths would, therefore, be reading possibilities, linear or otherwise, composed of a base, a backbone and their bundle of possibilities. If reading is a process in which people naturally get lost, when it comes to fragmented texts the challenge is even greater.

LongForm or Microcontent? An analysis of supports for digital content courseware.

Gomes, N. S.; Martins, R. X. and Azevedo. D. S. Page 4 of 17 
Studying online content, just as in the traditional way, is ultimately an individual process. The reader begins by exploring the basic material, then walks through the associated hyperlinks, and does not know where it will end. These various paths depend on one's familiarity with digital media and each reader relates to the content in a different way. It is convenient for teachers and multidisciplinary teams of support for production of digital educational materials organize and propose exploration and learning trails that contemplate the appropriate readers, but that also benefit the unfit readers, in order to help them at evolving in their personal difficulties, culminating the students' achievement of their learning objectives, proposed for each teaching unit. Organization in formats like that of the Microcontent is a strategy for organizing these tracks.

\subsection{Characteristics of the Microcontent format and its relation to Microlearning}

The first authors to use the term "Microcontent" were Jakob Nielsen and Hoa Loranger in the article "Microcontent: A Few Small Words Have a Mega Impact on Business". Nielsen and Loanger (1998, p. 01), defined Microcontent as a "key messages in a concise form: it can be used to describe an article or long blog post, add clarity to an interface, or encourage a desired behavior". The conception of the authors is far from the current use of the term, but it established that the purpose of Microcontent would be encouraging users to take some action.

More recently, Buchem and Hamelmann (2010, p. 02) have described Microcontent as an -information published in short form, with its length dictated by the constraint of a single main topic and by the physical and technical limitations of the software and devices that we use to view digital content today. For them, the Microcontent, when utilized within a Personal Learning Environment can be easily customized and distributed, allowing a high degree of control over learning and empowering the students to shape their own learning.

Microcontent has arisen by the need to fragment the contents to make them suitable for mobile devices and other technological artifacts, according to Silva, Vieira, Pereira and Braviano (2015). According to them, "[...] Microcontent emerges as innovative elements of pedagogical practices of these new learning models" (Silva et al., 2015, p. 03). Mobile devices, such as cellphones and tablets, meet the demands of fast and dynamic life rhythm and can accomplish multitasks. Because of these characteristics, Microcontent can be composed of a text, a video, audio, a picture, a diagram, a drawing or a photo; but also, by the varied combination of these items with each other.

The partitioned content in reduced fragments "[...] is not restricted to an idea of measurement of size, but rather to a unit, a module, and as such is dependent on the context in which it is inserted" (Silva et al., 2015, p. 03). Therefore, the Microcontent is defined by the subject topic that it approached and by the characteristics of where it is inserted.

Microcontent can be used as a strategy for continuous professional development like Buchem and Hamelmann argue (2010). According to them, with modern technologies, the so-called "didactics design" is currently organized with the student as a focus. Like so, the online study environment needs to be stimulating and organized so that it is initiated and administered individually by the student, rather than just a sequential proposition of steps and previous instructions that should be strictly followed by the students. It is therefore comprehended that the content would be "[...] co-created,

LongForm or Microcontent? An analysis of supports for digital content courseware.

Gomes, N. S.; Martins, R. X. and Azevedo. D. S. Page 5 of 17 
modified and used by students [...], distributed and both inside and outside of Learning Environment. This mobility of content across various platforms is supported by its light format" (Buchem \& Hamelmann, 2010, p. 06).

Small units of digital information would have the benefit of being organized flexibility allowing a complex integration of subjects. "The small format does not imply simplified pedagogical strategies. On the contrary, designing microlearning scenarios becomes even more complex, as it integrates various didactical approaches" (Buchem \& Hamelmann, 2010, p. 06).

Understanding this interaction design of content as an offer of various links about the studied subject, one realizes the need for the individual participation of the student in their learning process. It would not be enough for students to access the given information, but to relate to it, guided by the proposed paths, such as a script.

Therefore, it can be inferred that the term Microcontent defines an information unit that should be understandable in its own right. Its size and lightness are features that make Microcontent a favorable format for mobile devices utilization, due to features like the size of the screens and the keyboards, the brightness, battery life, and the mobile connection.

Through Microcontent use in education, the concept of microlearning emerges which is the result of an educative process that happens with condensed, short and specific content, for a virtual environment. One of the first authors to conceptualize microlearning was Theo Hug (2005, p. 01), that points "microteaching as any training that is applied in many steps." Microlearning would be efficient insofar as it allows the students to build, to experiment and to control their learning.

Microlearning is understood as short ways of learning and it is composed of interconnected activities: the result of a relationship between the reader and the available information in small content elements. Microlearning "[...] is a part of a dynamic, open and fragmented virtual environment in which small units of information can be individually produced, aggregated, utilized and reutilized" (Buchem \& Hamelmann, 2010, p. 04).

Some strategies are essential to guarantee the occurrence of microlearning, in other words, the availability of a certain amount of Microcontent in a Virtual Learning Environment or another course support is not enough. Buchem and Hamelmann (2010) see the need to encourage collaborative learning; to propose learning paths, but also to be prepared so that these sessions do not follow a pre-arranged script; to understand that microlearning occurs in coupled lightly phases, formed by an introduction, an activity and a closure; to design activities that can be generated by users at times of collaborative creation and participation; to utilize educational materials [...] that are actively coproduced, assembled and modified by students. Educational materials can be used as attachments or links to units, to direct the students' attention to key topics and to allow further exploration of the subject (Buchem \& Hamelmann, 2010 p. 07).

Based on this information, it is clear that using Microcontent for educational purposes is a process that demands a lot from the students. They need to be active, aware and content explorers; they need to be collaborative, attentive readers and clever digital navigators, 
so they can search for complements to their studies in the various Microcontents that address the same theme.

The question that arises from these demands is whether digital-age students are really as active and digitally literate to perform all these functions or if they cannot perform them, getting satisfied with the condensed or even shallow information offered in just one Microcontent link. In other words, although student proactivity is essential in any modality in which learning occurs, it is a movement of personal motivation. The success of their learning process should not be based on what is required by the study modality, on greater or lesser comprehension of the system, nor on the need of participating or exploring complementary content.

Therefore, the relevance of Microcontent application in complex contexts of DICTmediated teaching and learning is questioned. Due to its size limitation and its thematic topics, the Microcontent does not contemplate all the pedagogical mediation forms that can be supported by digital technologies. For courseware that need a deeper understanding of the covered topics more size and even a diversification of media items in its composition, there is a need to look for an alternative format.

\subsection{Longform: an alternative for the production of complex educational materials}

The need to look for an alternative to Microcontents appears not only in the education area but to all that utilize digital media to broadcast information. The media corporations, great users of Microcontents in its websites and portals, are among those who have been looking for other ways to spread their news. Given that the online communication industry works to gather audience by clicking, joining, sharing and engaging with its readers, communication is always innovating and improving the methods of making information available to the audience. In this sense, it is worth noting which movements that digital communications have made and also trying to use the success cases in digital mediated education.

LongForm format emerged in this scenario of searching for media innovation to a new audience. The term, defined by Longhi and Winques (2015), surpasses a simple long text, as the name seems to suggest. LongForm is a content presentation with the abundance of texts, images, videos and any other features that can offer a quality, accuracy and context rescue.

The abundant features of the LongForm format, which are also called multimedia elements should compose the informational material in a coordinated manner. You can insert textual elements with different fonts, various font sizes or information boxes; images highlighted by their size, color treatment, galleries or movements (e.g. GIFs Graphics Interchange Format); videos longer or shorter; animated or non-animated infographics and links that lead the reader to other content that complements the presented subject.

Productions that use the LongForm format present, besides multimedia items, other characteristics highlighted by Carvalho and Lima (2016):

a) a long and deep text, with a lot of content;

b) the use of HTML5 technology to merge screen media; 
c) nonlinear reading;

d) responsive design, in which the material is adapted to the media that the user has chosen to consume.

Therefore, a text composed in the LongForm format has, besides the extension, the feature of present more characters and even more pages of written content, all complemented by the multimedia items mentioned in the previous paragraphs. The number of items and their combination depends exclusively on the content producer's criteria, on the learning objectives, and on the course design. The American Longform.org portal was the LongForm movement forerunner starting the work in 2010. At that time, many large reports were published according to the model, which eventually attracted several followers, readers who identified with the style.

The LongForm format was born in journalism, and to these days it has been used exclusively in the communication field, most specifically in reporting in which more time and space are required for both production and information distribution. In this sense extant literature about this style, until then, only analyzes its application to journalistic reports.

However, the LongForm movement only to gain force after 2012, with the reporting of Snowfall ${ }^{1}$ by The New York Times, a multimedia report about a tragedy occurred during a Washington avalanche in February 2012 (Figure 1).

Some Brazilian journalistic vehicles already use the LongForm format in their productions. The Folha de São Paulo newspaper, for example, has had a section devoted to great multimedia reports since 2013, called Tudo Sobre ${ }^{2}$. The editions are composed by [...] long texts, open photos, audios, animated infographics and even an application that allows the internet user to 'fly' a helicopter over the reporting subject". (Lenzi, 2016, p. 163)

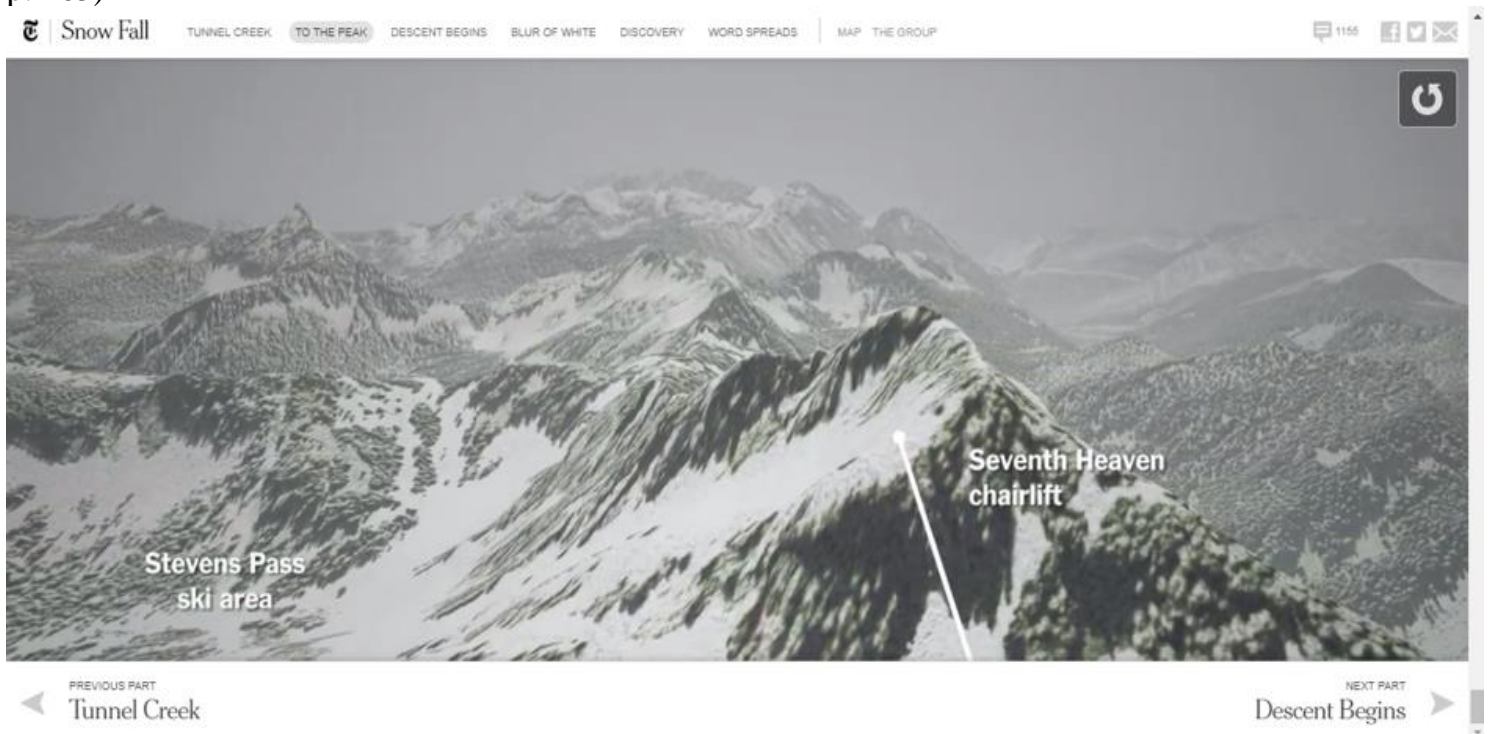

Figure 1 - Snowfall Report: navigation video on top of the mountain ${ }^{3}$

\footnotetext{
${ }^{1}$ http://www.nytimes.com/projects/2012/snow-fall/

${ }^{2}$ https://www1.folha.uol.com.br/tudosobre/

${ }^{3}$ http://www.nytimes.com/projects/2012/snow-fall/
} 
Such examples of the LongForm format in the communication area, which have large journalism corporations as precursors, indicate the format potentialities and provide the possibility of proposing its use in the educational area. A technology-mediated course, mobile or otherwise, does not need to be limited to the Microcontent format, which would risk a possibility of offering only superficial or simplified information and would undermine the teaching and learning process.

Based on what happens in face-to-face teaching, in which teachers can, besides working on the contents, propose in-depth readings, reflections and seek to favor intertextuality with different themes and areas, the research reported in this paper explores the uses of LongForm format into composing digital learning materials. Considering the possibilities of construction through multimedia resources and the success it has obtained in the journalistic communication field, the use of the LongForm format, an alternative to Microcontent, avoids the presentation of fragmented content that impair the students' total comprehension of a content, as it tends to simplify the information.

\section{Method}

In order to compare the use of LongForm and Microcontent formats, applied for the study of the educational content, an exploratory research was designed in a quantitativequalitative approach, with the initial hypothesis that LongForm is best suited for use in most complex educational content. The research aimed to compare the experiences of using the two models, the participants' behavior and, consequently, to identify the adequacy and the inadequacy of each format for complex content.

Courseware in LongForm and Microcontent formats, respectively referred to as Model 1 and Model 2, were elaborated addressing the same content and these materials were used as study activities in an undergraduate discipline offered in the hybrid course ${ }^{4}$. The research took place in eight undergraduate courses at a private university located in Minas Gerais state of Brazil that has, besides its headquarters, four other campuses in cities of the same state.

The educational material denominated as Model 1 was made according to the characteristics of the LongForm format. Model 1 has used several resources, so-called multimedia elements, to compose the content about water subject, that the students would have to dominate. The items found in a journalistic article published on the Internet by a Folha de São Paulo newspaper were inserted in the material, which were the textual elements of differentiated fonts that contained various sizes of letters and subtitles, images highlighted by their size, colors and galleries, infographics, information boxes, and video (Figure 2). Authorization to use the journalistic article website was granted by the newspaper research department. It was necessary due to copyright and because it would be necessary to copy the content and transfer the content to another electronic address in order to insert the encoding that allowed the monitoring of access and reading of the content by the participants.

\footnotetext{
${ }^{4}$ Hybrid course are names commonly used to describe courses in which some traditional face-to-face has been replaced by online learning activities.
}

LongForm or Microcontent? An analysis of supports for digital content courseware. Gomes, N. S.; Martins, R. X. and Azevedo. D. S. $\quad$ Page 9 of 17 


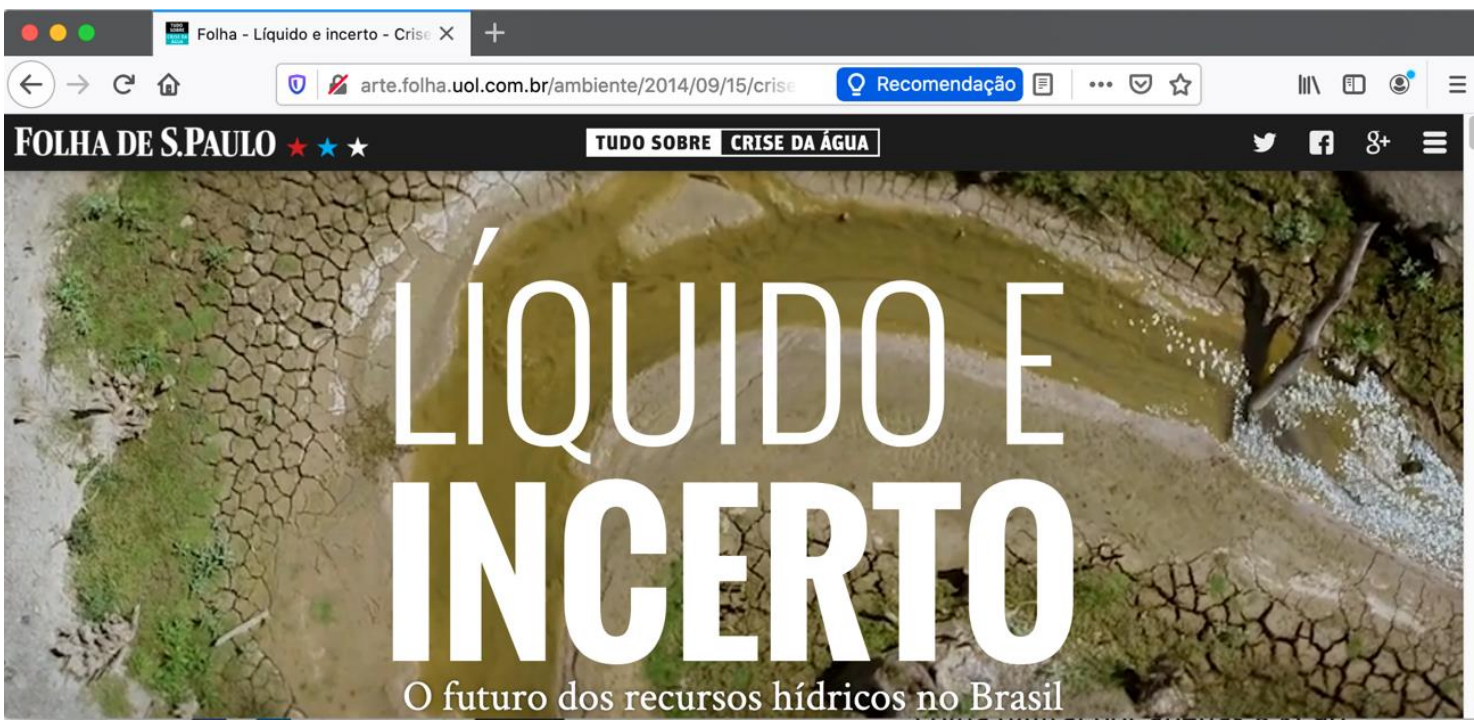

Figure 2 - Longform used in Model 1 educational material ${ }^{5}$.

The items have followed the characteristics highlighted by Salaverría (2014), whom observed him the importance of using different resources to would not disperse the reader, to enrich the reading, to avoid being redundant, to hierarchize the information and, finally, to adapt information and multimedia elements so that the media's support throughout students would access the content is respected. This way has used a neutral white background, contrasting fonts, rotating images, and plenty of empty spaces, which helped avoid the content from its to become too heavy or confusing.

The productions that use the LongForm format present, besides the multimedia items, other features that were highlighted by Carvalho and Lima (2016), such as the use of the long and in-depth text, but with enough content to explain the theme in question. In other words, the format is characterized as ideal for dense subjects that require great explanations.

In turn, Model 2 - elaborated according to the specificities of Microcontent - followed all the characteristics of this format, which are understood as delimited content units accessible through specific addresses and that can be available on different platforms.

That way at Model 2 -Microcontent offered the students a page with five links, a list of short news, combined together, which overall approached the same themes of Model 1 with great similarity, but independent of each other. The following contents was organized in Model 1:

a) A distribuição da água no mundo - Mundo Educação site . $^{6}$

b) Brasil e as mudanças climáticas - WWF site ${ }^{7}$.

c) Reservatório da Cantareira atinge menor nível em 39 anos -Folha de São Paulo journal ${ }^{8}$.

\footnotetext{
${ }^{5}$ http://arte.folha.uol.com.br/ambiente/2014/09/15/crise-da-agua/

${ }^{6} \mathrm{http}: / /$ mundoeducacao.bol.uol.com.br/geografia/a-distribuicao-agua-no-mundo.htm

${ }^{7}$ http://www.wwf.org.br/natureza_brasileira/reducao_de_impactos2/clima/politicas_de_clima/brasil_muda ncas_climaticas/

${ }^{8} \mathrm{http} / /$ www1.folha.uol.com.br/cotidiano/2014/01/1405442-reservatorio-da-cantareira-atinge-menornivel-em-39-anos.shtml
}

LongForm or Microcontent? An analysis of supports for digital content courseware. Gomes, N. S.; Martins, R. X. and Azevedo. D. S. 


\section{d) Clima urbano: Grandes cidades são ilhas de calor - - Universo OnLine portal' .}

By offering these links, which were organized on a single Home Page that has hinted that all addresses should be visited, the individual participation of each student has occurred. Buchem and Hamelmann (2010) also stated that it would not be enough for the student to simply access the information, but also to relate its, guided by proposed paths, like a script.

Microcontent, when used for educational purposes, especially in more complex content, was considered to be a very demanding process for students, making them active, explorers, collaborative, attentive readers, and smart digital navigators, in order to search within the various Microcontents that address the same theme, which are complements to their studies.

This research had like participants those students enrolled in the course that authorized the use of their personal and browsing data while reading for data collection, and who have answered the following question: "When you be studying, your actions on this page will be monitored for academic research, do you agree?". This question has appeared on the screen via a pop-up message in the first access to the course. Thus, with these authorizations, individual data regarding utilization, preference, and navigation were automatically collected by Bots ${ }^{10}$ and were inserted in the teaching material pages of those students. The Bots were created with the support of teachers and computer science students from the researched university. All the content of the teaching materials was temporarily copied to a specific web server and coding was inserted that allowed the monitoring of the study actions of the participants while using the website. Such monitoring was carried out using Google Analytics ${ }^{11}$ resources and small snippets of JavaScript ${ }^{12}$ program, which made it possible to capture access data, triggered options, navigation preferences, estimated times, viewed videos, among others, of each research participant.

However, data from students enrolled in the course, but who were not performing the assessment activities within the time frame provided in the institution's Academic Calendar were excluded from the research, and also the data from those who have not wished to be part of the study or those which have not authorized by clicking on "Disagree" in the authorization message.

In the quantitative step, the bots collected the following: (a) from Model 1 - LongForm: data regarding reading time, media items on which the student clicked - such as image gallery, video, next page access button - and video retention time; (b) Model 2 Microcontent: data for the five links the student clicked, in other words, if he clicked

\footnotetext{
${ }^{9}$ https://educacao.uol.com.br/disciplinas/geografia/clima-urbano-grandes-cidades-sao-ilhas-de-calor.htm

${ }^{10}$ Bots are autonomous programs on a network (especially the Internet) that can interact with computer systems or users.

${ }^{11}$ Google Analytics is an Application Programming Interface (API), a Google tool for use by website developers. With it, it is possible to track details about the visitation and statistics of a web page and quantify as daily visits.

12 Javascript is a scripting language (a part of the code was inserted into an HTML page) embedded in a Web page. It helps web page creators to make pages more dynamic and complex. The Java code snippets were used for mouse tracking, screen scrolling, choices, and time in each study unit.
} 
more than one link or all of them. The objective was to identify, in the first model, if the student explored all the resources offered and, in the second model, if the student was interested in exploring one of the available links or if one item of news information was enough.

In the qualitative step, whose data were obtained through descriptive answers to questions presented to the student after the end of the activity, it was possible to identify the utilization perception of students on the experience of using the models.

The analysis of quantitative data was performed using descriptive statistics and qualitative data were analyzed by the content, inspired by Bardin (2010), with a categorization of approximations and distances in both formats, the LongForm and the Microcontent.

Of the 488 students enrolled in the surveyed courses, 67 students agreed to participate in the survey, which represented $13.72 \%$ of the total. Greater accession was expected, but the nearly 70 participants formed a heterogeneous group, through which it was possible to identify different perceptions of use regarding the offered materials. Of the 67 participants, 19 students used Model 1 - the LongForm, and 45 students used Model 2 the Microcontent, and three agreed to participate, but they did not respond to the activity, giving up their participation in the survey.

\section{Results and Discussion}

Considering of the limits that are necessary to concise a paper published in a journal, the discussion presented in this section has been focus on the main differences found between the LongForm and Microcontent formats based on statistical results and content analysis of the participants responses. The responses to the questionnaire were quantified and categorized based on perceptions of difficulties or facilities encountered during the tasks proposed in Models 1 or 2.

In Model 1 (LongForm) the answers were grouped into the assumptions described below. Negative aspects:

- Extensive and tiring teaching material.

- Long and confusing text.

Positive aspects:

- Difficult to understand what was requested.

- No difficulty in performing tasks;

- Clear text, objective and audiovisual resources that assist;

- Reading holds attention.

In Model 2 (Microcontent), the assumptions resulting from the groupings of responses were as follows.

Negative aspects:

- Short time available to access all links;

- Extensive task.

- Difficult to understand what was requested.

- Many important items within one didactic material with several links.

LongForm or Microcontent? An analysis of supports for digital content courseware.

Gomes, N. S.; Martins, R. X. and Azevedo. D. S. 
Positive aspects:

- Access to the content of the links helped in the study.

- Although restricted, the content offered was sufficient.

- Simple task;

- Didactic material very simple and clear.

Regardless of the format used (Model 1 or 2), it was observed that biggest challenge to study was the digital reading ability of each student. Mastering technologies to the point of using them as a facilitating tool in the knowledge construction is an individual process, and a result of their own experiences and skills.

Therefore, the person when is studying needs to know how to deal with these tools, to know how to access the contents and to master the languages, something that would require proactivity. It would be necessary to know the digital resources, identify and make the correct use of equipment and controls, to finally use the technologies in the learning process. Agreeing with Chartier (1999), it was observed that each reader faces a sequential flow of texts, whether on screen or not, and each one needs to know what to do with that information. This way, each new support triggers a new way in which each person relates to the content, that is to say, each new technology or support demands new ways of reading.

Students were presented with two formats composed by different informational units: one with an organizational structure, a navigation path sequence and multimedia resources integrated into a single material without hierarchical access, and other with a hierarchically structured sequence of links, each being a mini news report, made up of a short text plus an image or a chart. Regardless of whether students are what Santaella (2004) calls as laypeople, experts, wandering, detectives or predictors, they would need to be able to navigate through the information, to have an overview of the content, to understand the navigation possibilities and clickable items in it, and to read quietly in search for effective learning. But, due to Marchuschi (2007) states, the navigation paths, despite being laid as a result of the author's action, only materialize in the hands of the reader. It is up to the readers to decide which paths to take facing the reading possibilities, linear or not, that are in front of them.

Through the application of this research, it was observed that regardless of the reading paths that each student took, 97\% achieved good results, reaching the goals set by the teacher for the activity. This arouses two possibilities: there was the effectiveness of interaction with the available information, generating learning possibilities during the study and/or the verification process applied to evaluate was not related to the support material organized for the study. The best results in achievement were found among participants who studied with Model 1 - LongForm, but this is not enough, to indicate that this support material has an influence on academic performance.

The results bring by Model 1 - LongForm had more positive reports about didactic material. There were 58\% positive responses related to the material, against $5 \%$ negative reports. Into students' perception, reading was been easy, regardless of the equipment used to access it, considering that no restrictions were pointed out of the collected perceptions of the device, which includes usability and ergonomics. The great difference among participants who accessed themselves desktop content and those have used mobile 
devices centered on the reading time: 2.09 minutes when accessing their desktops and 11.06 minutes to has been accessing others via mobile devices such as tablets and cellphones.

The content offered by the LongForm model, while addressing the same theme as the content of the compared format, was all offered in a single two-page material, resulting in complex and dense content that required concentrating and exploratory reading. As a result, participants had low access $(10 \%)$ to the second page of content, which was the other half of the material. Neither the media used to access and the consequent retention time they demanded for reading, not the inadequate access to the second half of the material interfered in the grades that were obtained by students, considering that the values were either 8 or 10 points. The good quality of the answers is because the "water" theme is generally known; teachers have had the opportunity to work well through the content modules that preceded the activity and, finally, by the features themselves in the LongForm model, which was enough material for the students to answer the proposed question - by offering various multimedia elements and a good amount of textual information in its first part.

In turn, Model 2 - Microcontent - presented different perceptions about the material. There were $47 \%$ of positive reports and $15 \%$ of negative reports related by participants. Students were also able to read easily, regardless of the support used to access it, considering that none of the collected perceptions were their observations related to the device, such as usability or ergonomics. The Desktop vs. Mobile Devices relation was also centered on reading time, which was of 2.26 minutes among Desktops and of 6.45 minutes among students using tablets and mobile devices. The content was better explored by students, with a more balanced number of visits among all available links, but with a gradual decline from the first to the last.

Many items and navigation paths have not been explored, and Marchuschi (2007) explains that it is likely that many of the reading problems are unrelated to the hypertext and to digital materials themselves, but "[...] instead to the type of relationship with the texts in general. People without the habit of reading easily get lost reading a newspaper and even more when they are faced with the hypertext that does not progress with an immediate vision of the path taken" (Marchuschi, 2007, p. 205). Therefore, it is necessary to consider that, besides the characteristics of each digital format compared, the already known ability to understand a conventional text, as stated by Leão (2005), remains basic and necessary.

In Model 2 - Microcontent, consisting of a page with consolidated textual information and a series of sequential links, about $30 \%$ of all the students who accessed the first link clicked on the last one, a much higher rate than that of students who opened the second page of the content from Model 1 - LongForm (10\%). Santaella (2007) argues that the behaviors of this type are linked to the particular way each person has to structure the information so that it would make sense and become knowledge. A linear sequence of links presents itself to the virtual reader as a space where information is joined and arranged for readers to access as they see fit; even if they do not click all the links, or access them in a different order, because that is the prime characteristic of hypertexts, "[...] the hypertext is not meant to be read from the beginning to the end, but rather through searching, discoveries, and choices. [...] The flexible structure and the nonlinear access of hypertext allow divergent searches and multiple paths within the document"

LongForm or Microcontent? An analysis of supports for digital content courseware.

Gomes, N. S.; Martins, R. X. and Azevedo. D. S.

Page 14 of 17 
(Santaella, 2007, p. 308). Agreeing with the author, this work is aligned with the thought that the highest rate of access to the links provided was due to the freedom of choice for the navigation process and also because the content is smaller and, consequently, more accessible.

Following the navigation paths performed by each student was an interesting exercise that proved the unpredictability of network browsing, as stated by Leão (2005). The author uses an example when speaking about the difficulties in predicting an event: "blow a balloon and when it is in a good size, without tying it, release it. She asks: 'is it possible to predict the behavior of the ball, describe the trajectory it will draw in space?' (Leão, 2005, p. 57). She affirms that the same thing happens in hypermedia environments, as it is impossible to predict the choices the user will make. "There are so many factors that interfere with the path to be traveled on the Net, that it can be said that we are also facing hyper complexity" (Leão, 2005, p. 57).

\section{Final Considerations}

Through the research application, it was possible to realize that the biggest challenge to study and to compare didactic materials for online study is not necessarily related to the organization format, but the digital reading ability of each student. After all, mastering technologies to the point of using them as a facilitating tool in the process of building knowledge is an individual process, the result of their own experiences, skills, and competences. Regardless of whether the material that the student contacted was LongForm or Microcontent, that student would need to be able to read online.

The navigation paths, despite being laid out, were materialized through the reader's action only. Many items and navigation paths have been unexplored, and this reality may be related to the lack of reading habits, digital or not. This student behavior can also be linked to each person's particular way of structuring information so that it makes sense and becomes knowledge, and therefore it is unconsidered a problem. It is likely that once the navigation path is defined by the reader, some of the participants considered that $50 \%$ of the content read - in the case of Model 1 - LongForm; and only one, two or three of the offered links - in the case of Model 2 - Microcontent, were enough to respond the activity, adding the didactic material information to previous knowledge about the subject. Even if the students have not clicked on all available tools or if they accessed the links out of order, it just proves the primary feature of digital texts is that paths cannot be predicted, they can only be available.

By searching for an alternative for didactic material production that would not simplify the contents and that would not harm the educational process, the research identified that the Microcontent format - once it needs to fragment the information in micro-units and demands that the students read more than one unit to build a meaningful comprehension about the subject at hand - remains a viable format for educational use in digital media, especially when it comes to less dense or complex subjects, like review topics and supplemental materials.

Finally, it was confirmed that the LongForm presents itself as a viable alternative for online studying because it is constituted by a single virtual space where larger texts and varied multimedia resources can be inserted to enrich the material and to allow the teacher

LongForm or Microcontent? An analysis of supports for digital content courseware.

Gomes, N. S.; Martins, R. X. and Azevedo. D. S.

Page 15 of 17 
to offer the students all the information, resources, additional items and whatever else is needed to work on the study unit in question. The students took more time to read in the LongForm, but it is inferred that this is due to the number of elements inserted in the material that require more careful reading to understand the data. According to the various authors were cited in this work, once the content was not fully explored, it can be concluded that the individual reading ability - as well as the ability to navigate online, in other words, the digital literacy - interferes in this process in a way unrelated only with the format, as evidenced by the participants' perception reports.

Therefore, the use of the Microcontent format is indicated to offer online learning materials intended for revision, the initial presentation of supplemental materials such as "learn more" links and for the use in minor subjects, both in extension and conceptual deepening. And it is proposed the use of LongForm - usually found in journalistic content of major reports - in distance education, in reaching didactic materials for regular study, as complete didactic modules composed of theory, examples, exercises, illustrations, videos and activity proposals; in other words, in larger issues, both in length and in conceptual density.

Received: April 9, 2020

Accepted: October 22, 2020

Published: January 8, 2021

Gomes, N. S., Martins, R. X., \& Azevedo. D. S. (2020). LongForm or Microcontent? An analysis of supports for digital content courseware. RED. Revista Educación a Distancia, 21(65). http://dx.doi.org/10.6018/red.422371

\section{Funding}

This research has not received any specific grant from funding agencies in the public, commercial or non-profit sectors.

\section{References}

Amante, L. \& Morgado L. (2001). Metodologia de concepção e desenvolvimento de aplicações educativas: o caso dos materiais hipermedia. Discursos: língua, cultura e sociedade, 27-43. Retrieved from: http://hdl.handle.net/10400.2/4348.

Bardin, L. (2010). Análise de conteúdo. (L. A. Reto \& A. Pinheiro, Trad.). Lisboa: Edições 70.

Buchem, I., \& Hamelmann, H. (2010). Microlearning: a strategy for ongoing professional development. eLearning Papers, 21(7), 1-15. Retrieved from: http://dx.doi.org/10.4236/ce.2015.623254.

Carvalho, D.R., \& Lima, V.A. (2016). A utilização de elementos multimídia no jornalismo digital: um raio-x do especial "Crime sem castigo - tudo sobre o contrabando no Brasil" da Folha de São Paulo. Temática, 12(11). Retrieved from: http://dspace.bc.uepb.edu.br/jspui/bitstream/123456789/10405/1/PDF\%20\%20Deise\%20Ribeiro\%20Carvalho.pdf.

Chartier, R. (1999). A aventura do livro: do leitor ao navegador. Trad. Reginaldo de Moraes. Editora Unesp/Imprensa Oficial do Estado, SP.

LongForm or Microcontent? An analysis of supports for digital content courseware.

Gomes, N. S.; Martins, R. X. and Azevedo. D. S.

Page 16 of 17 
Eisenkraemer, R. E. (2006). Leitura digital e linguagem cifrada dos internautas. Texto Digital, 2(2). Retrieved from: https://doi.org/10.5007/\%25x.

Gabrielli, S., Kimani, S. \& Catarci, T. (2017). The Design of MicroLearning Experiences: A Research Agenda (On Microlearning). Retrieved from: https://goo.gl/mB2GdY.

Hug, T. (2005). Microlearning: a new pedagogical challenge (introductory note). na. Retrieved from: https://www.researchgate.net/profile/Theo_Hug/publication/237397162_Microlea rning_A_New_Pedagogical_Challenge_Introductory_Note/links/54009baf0cf23d 9765a3f648.pdf.

Leão, L. (2005). O labirinto da hipermídia: a arquitetura e informação no ciberespaço.

Lenzi, A. (2016). Multimidialização como valor-notícia de construção: a experiência do UOL TAB. Revista Latino-americana de Jornalismo. Retrieved from: http://periodicos.ufpb.br/index.php/ancora/article/view/28305.

Longhi, R. R., \& Winques, K. (2015). O lugar do longform no jornalismo online. Qualidade versus quantidade e algumas considerações sobre o consumo. Brazilian Journalism Research, 11(1), 110-127. Retrieved from: https://doi.org/10.25200/BJR.v11n1.2015.693.

Marchuschi, L. A. (2007) A coerência no hipertexto. In.: Carla; C. \& Ana Elisa R. (Eds.). Letramento digital: aspectos sociais e possibilidades pedagógicas. $2^{\mathrm{a}}$. Ed. Belo Horizonte: Ceale-Autêntica.

Moore, M. G., Kearsley, M. (2011). Distance Education: A Systems View of Online Learning. Cengage Learning.

Nielsen, J. \& Loranger, Hoa. (1998) Microcontent: a few small words have a mega impact on business. Retrieved from: https://www.nngroup.com/articles/microcontenthow-to-write-headlines-page-titles-and-subject-lines/.

Salaverría, R. (2014). Multimedialidade: informar para cinco sentidos. In: Canavilhas, J. (Org.). Webjornalismo: 7 caraterísticas que marcam a diferença. Retrieved from: http://www.labcom-ifp.ubi.pt/ficheiros/20141204201404_webjornalismo_jcanavilhas.pdf.

Santaella, L. (2007). Linguagens líquidas na era da mobilidade. São Paulo:Paulus.

Santaella, L. (2004). Navegar no ciberespaço: o perfil cognitivo do leitor imersivo. São Paulo:Paulus.

Silva, M. D., Vieira, M. L. H., Pereira, A. T. C., \& Braviano, G. Microconteúdos na forma de explainer videos para a educação. Uma revisão integrativa. Retrieved from: https://www.researchgate.net/publication/297918827_MICROCONTEUDOS_NA _FORMA_DE_EXPLAINER_VIDEOS_PARA_A_EDUCACAO_UMA_REVIS AO_INTEGRATIVA.

Willey, D. A. (2002) Connecting learning objects to instructional design theory: A definition, a metaphor, and a taxionomy. Retrieved from: http://reusability.org/read/chapters/wiley.doc 